\title{
Educational Robotics for Communication, Collaboration and Digital Fluency
}

\author{
Ivaylo Gueorguiev ${ }^{1}$, Christina Todorova ${ }^{1}$, Pavel Varbanov ${ }^{1}$, \\ Petar Sharkov ${ }^{1}$, George Sharkov ${ }^{2}$, Carina Girvan ${ }^{3}$, Nikoleta Yiannoutsou ${ }^{4}$ \\ and Marianthi Grizioti ${ }^{4}$ \\ ${ }^{1}$ European Software Institute - Center Eastern Europe (ESI CEE), Sofia, Bulgaria \\ \{ivo, tina, pavel\}@esicenter.bg; \\ petarsharkov@gmail.com \\ ${ }^{2}$ European Software Institute - Center Eastern Europe (ESI CEE), Sofia, Bulgaria \\ Faculty of Mathematics and Informatics, Plovdiv University, Plovdiv, Bulgaria \\ geshadesicenter.bg \\ ${ }^{3}$ Cardiff University, Cardiff, Wales, UK \\ girvancecardiff.ac.uk \\ ${ }^{4}$ UoA ETL, National and Kapodistrian University of Athens, Athens, Greece \\ \{nyiannoutsou, mgriziot\} @ppp.uoa.gr
}

\begin{abstract}
This paper is the experience-based summary of the work with the design, implementation and results from an "Educational Robotics and Creativity Workshop” under the EU funded Horizon 2020 project „ER4STEM - Educational Robotics for Science, Technology, Engineering and Mathematics“. This paper gives an overview of the empirical data obtained from the post-workshop questionnaires, completed by the participants from 13 educational robotics workshops, performed in 7 schools (public and private) in Bulgaria with 312 students (142 girls and 170 boys) in the time period from February 16, 2016 until May 31, 2016. The students were between 7 and 14 years old with the majority of them aged between 9 and 10 years old.
\end{abstract}

Keywords: educational robotics, creativity, collaboration, communication, digital fluency, Arduino, visual programming, robotics in education.

\section{$1 \quad$ Background}

Today, especially within the context of the rapidly developing technological environment, we hardly ever fail to realize the need of an educational system built on powerful ideas with personal meaning to keep students motivated to study the STEM disciplines. Most children are learners by nature, meaning they manifest interest to learn more about the world they live in - about how things work, about mechanics and technology. To keep this interest alive, especially when it comes to science, technology, engineering and mathematics, we believe that we have to cultivate in students a learning attitude of excitement, personal interest and social meaning. 
As a result of the EU funded Horizon 2020 project, "ER4STEM - Educational Robotics for Science, Technology, Engineering and Mathematics", the European Software Institute - Center Eastern Europe, with the direct support and contribution of the project consortium, was able to develop and implement with more than 600 students an educational robotics workshop with the aim to promote and prove in practice the value of those beliefs.

The authors base this article on the empirical data obtained from the post-workshop questionnaires, completed by the participants from 13 educational robotics workshops, performed in 7 schools (public and private) in Bulgaria with 312 students (142 girls and 170 boys) in the time period from February 16, 2016 until May 31, 2016. The students were between 7 and 14 years old with the majority of them aged between 9 and 10 years old.

This paper aims to present in brief the experience of working on this educational robotics workshop in its entirety, including the necessary overview of the methodology underlying the workshop. The article explores the feedback received in respect to the workshop objectives to encourage the development of skills in the participants in the field of creativity, digital fluency (technology, engineering and science), communication and collaboration. With this paper, we aim to contribute to the promotion of the importance of such activities within the academic life of both students and pedagogues, based on the results received throughout an extensive evaluation process and interviews with teachers.

Last, but not least, this paper represents the combined effort of a group of robotenthusiasts to share their experience with robotics as a tool to teach $21^{\text {st }}$ century skills, along with subjects of digital fluency, and to share the joy of applying robotics as a way to keep students curious to learn about the world.

\section{Workshop Design}

As the nature of this paper requires a certain level of knowledge on the multi-layered methodological background of this workshop, this paper will give a brief overview of the pedagogical approach, underlying the design of the educational robotics workshop. A review of the social orchestration will follow, along with a description of the basic hardware and software solutions, designed to fit the pedagogical purposes of this workshop. Lastly, this chapter will provide information about the goals of this workshop, related to promote a set of $21^{\text {st }}$ century skills, as well as a presentation of the authors' understanding of those skills.

\subsection{Pedagogical Approach}

The basic pedagogical theory underlying the design of all educational robotics workshops within the ER4STEM project, including ESI CEE's educational robotics workshop for creativity, is constructionism. According to the project's understanding of constructionism, a constructionist pedagogical setting is one, where learning is connected 
to powerful ideas inherent in constructions with personal meaning for the students [1]. Furthermore, ER4STEM places special emphasis on the social dimension of the construction process aiming to introduce the maker culture to the students (i.e. sharing, discussing, reflecting around constructions) cultivating a learning attitude growing out of collaboration-based experiences. [2][3]

The pedagogical approach, as well as the background for the elaboration of the educational robotics workshops within the ER4STEM project are coordinated and structured with the means of an Activity plan template. The template provides a generic design instrument that identifies critical elements of teaching and learning with robotics based in theory and practice and is expected to contribute to the description of effective learning and teaching with robotics.

With the above considerations in mind, the Activity plan template developed for designing Robotics activities for the ER4STEM workshops, addresses the following aspects: a) Focus and resources: reference to the different domains involved, different types of objectives, duration and necessary material; b) contextual information regarding space and characteristics of the participants; c) social orchestration of the activity (i.e. group or individual work, formulation of groups etc.); d) a description of the teaching and learning procedures where the influence of the pedagogical theory is mostly demonstrated; e) expected student constructions; f) description of the sequencing and the focus of activities; g) means of evaluation. [4]

\subsection{Workshop Setting}

ESI - CEE, designed and developed an activity plan focusing on the use of educational robotics for creativity and addresses boys and girls within the age group 8-12 years old. This activity plan is implemented in a set of 13 different workshops taking place in the school with the status of extra-curricular activity. This means that the workshop does not need to be aligned to the curriculum - although it can be - and student participation in the workshop is not connected in anyway (e.g. in terms of grades) to the subjects they are following in school. The workshop takes place during school hours; the duration of each workshop is not more than eight hours in total and it is usually divided into two consecutive sessions of equal duration.

Two main challenging requirements were identified by the development team. On the one hand, it was of utmost importance that the workshops are designed to adequately align to the environment of a regular, in-school and at-class context of public general education schools. In Sofia, Bulgaria, where most of the workshops were conducted, a regular school class consists of students, anywhere within the range of 24 to 28 students. That number of students, supposed to work simultaneously, presented a challenge to the design of the workshop

On the other hand, a feasible workshop for this context, had to be of a duration, not surpassing 8 hours. As mentioned above, the design team, in most cases, chose to conduct the workshops in two consecutive sessions of equal duration. The brevity of this time frame was challenging for the design of an adequate creativity program. This posed the need for the team to optimize the other sessions in their entity, including 
materials and pedagogical approach, so that sufficient time and attention could be dedicated to the so called "soft sessions" of the workshop, namely MODULE 4: ROBOT'S TOUCH and MODULE 5: LET'S IMAGINE. A solution identified by the team, was to lead the soft sessions, between the technical sessions (MODULE 3: CONSTRUCTING A ROBOT and MODULE 6: PROGRAMMING A ROBOT), thusly providing sufficient time for the tutors to check the robots for short circuits and other dangerous mistakes, and provides students with the opportunity to think creatively and not overburden them with consecutive technical sessions.

The workshop is structured into 7 /seven/ modules:

\section{MODULE 1: INTRODUCTION AND PRE-EVALUATION}

The tutors introduce themselves and explain what they do and why they came to the school. They also explain what they find fascinating about robots and what the task is for the specific day. Next, they discuss with the students whether they like robots, if they have had any experience with them in order to informally introduce themselves by their interest within the topic of robotics. The purpose of this module is for the tutors "to break the ice", trigger the students' interest in robotics, become familiar with the students, get to know some names and show that they are interested to learn with whom they are going to work with. This first module is important for the specific setting in which the workshop is implemented: i.e. external tutors, collaborating, for 8 hours only, with students and teachers they haven't seen before, which means they are not acquainted with the norms of the specific school and they are not familiar with the specifics of the classrooms participating in the workshop.

\section{MODULE 2: WHAT IS A ROBOT}

The tutors ask students "what is a robot" to generate ideas what are the key components of the robots. Once a student generates an idea, the tutors encourage the others to comment and contribute. This module aims to engage students in a meaningful discussion about robotics and inspire their imagination, thus providing basic information about robotics and influencing positively their attitudes about the workshop.

\section{MODULE 3: CONSTRUCTING A ROBOT}

In this module, students are introduced to the robotic kit. Tutors show the different elements in the kit and say a few words about their purpose. They show, as an example, the assembled kit, to motivate the students and give them an idea towards what they are working on. Students are encouraged to shift roles within their team, so that everyone could learn and everybody participates. This module is intended for students to collaborate with their teams, gain practical experience and become confident that building a robot is not difficult when in a team.

\section{MODULE 4: ROBOT'S TOUCH}

Once students build their robots, the tutors demonstrate in action different types of robots such as NAO, VGo, omnidirectional robots, the Finch robot and facilitate a Question and Answer session. The purpose of this module is to showcase different robots, with various applications, but, regardless, similar elements to what they already 
know, after assembling their robot. Showing similarities between the project, that the participants have just completed, and more complex robots, encourages students' confidence in their skills and knowledge about robots. In addition, students are inspired to think about and imagine different robots and their application in the real life.

\section{MODULE 5: LET'S IMAGINE}

The tutors engage the participants in a discussion on what creativity is and how important it is in everyday life. They are using a set of predefined games aiming to demonstrate different aspects of creativity and logical thinking. The goal of those game is to put participants in a creative mood and liberate them from some predefined notions on how the world functions in order to stimulate them to find "out-of-the box" and "crazy" solutions to a given problem. The purpose of this module is to inspire students to believe in the value of their ideas and to boost their confidence to openly share with others their ideas on various applications of robotics.

\section{MODULE 6: PROGRAMMING A ROBOT}

The tutors say a few words about the basics of programing with Scratch and how specific blocks are used to control the motors and the sensor. Each team uses the "set up" block to switch on the robot. The teams are left to experiment with the blocks, their functions, and the ultrasonic sensor (to measure the distance between the sensor and obstacles). The students have to "discover" how to program the robot, so that it would turn left and right, around its center, forwards and backwards at a different speed. The purpose of this module is for the students to gain programing skills and to have fun programming.

\section{MODULE 7: FINAL EVALUATION}

Evaluation session is held for students to present their achievements and evaluate their experience. Group and/or individual interviews are conducted and students fill out Post-Workshops Questionnaires.

The workshop implementation team consists of 3-4 tutors for a workshop with the maximum number of 30 participants. Furthermore, the above activity is designed for indoor implementation only within an adapted, but yet regular school setting. The adaptation usually involves the positioning of furniture - chairs, tables, computers, etc. aiming to create a makers' space for the participating students and facilitate group work.

Groups of 3-5 students are formed under no specific criteria. Workshop tutors delegate the responsibility of choice of teammates to the students themselves. A reason for this is the belief that if students are able to sit together, based on pre-established friendships, they would generally manifest a more positive attitude towards the workshop and the educational activity. On a rare occasion, schoolteachers would form groups, mainly due to disciplinary concerns. In cases of students with disabilities, the implementation team responds according to their special education needs. 


\subsection{Robotics Artefacts}

For the purposes of this educational robotics workshop, and in alignment to its pedagogical purposes, the European Software Institute - Center Eastern Europe has developed a custom Arduino-based robotics set.

In order to encourage the implementation of innovative technology in the education process on a local level, ESI CEE aimed at creating a cost-effective kit with easily replaceable and adaptable standard components.

The elements in the robotics kit are connected through a breadboard using wires. Moreover, the mechanical parts are fixed together with plastic pins which allows for them to be easily assembled and disassembled many times. The assembled robot is a small tank that can be controlled with either a PC using USB cable, or a Bluetooth module. Furthermore, the robot can run autonomously through a program code, uploaded to the controller.

Among the advantages of the created platform, in comparison to other robotics platforms for young students in which the electronic components are not directly visible (i.e. "black box"), the ESI CEE Arduino robotics kit uses, with some minor modifications, original engineering elements such as Arduino Uno board or other adapted compatible microcontrollers, ultrasonic sensors, motor drivers, LEDs and resistors. This way, young researchers are enabled to make their first steps in electronics and robotics by experiencing technology in a way they most likely rarely see it - as a white box. The final artefact is a robot-tank, assembled with the use of a visual guide, consisting of photos only, allowing children to learn by doing and experimenting.

\subsection{Digital Artefacts}

In addition to the Arduino IDE, ESI CEE adapted a program code that allowed younger students to control the robot using visual languages such as Scratch and Snap.

The implementation team chose visual programming software as an appropriate version for younger learners to overcome some of the predominantly age-based difficulties of programming, while still enabling children to experience and learn the logic and concepts behind programming.

ESI CEE chose the desktop version of Scratch for most of the workshops, reason being that this way, avoiding internet connectivity issues interfering with the workshop's implementation process, becomes easier. Furthermore, limited internet connectivity mitigates safety risks for children during the workshop.

ESI CEE used s2a_fm software to control the Arduino Uno board through Scratch or Snap. The team developed custom blocks to set up the robot for work, to visualize data from the sonar sensor and to control each of the motors through numerical values between -100 (max speed of the motor backward) to 100 (maximum speed of the motor forward) while 0 value stops the motor. 


\section{$2.5 \quad 21^{\text {st }}$ century skills}

Based on an extensive research of the literature for the $21^{\text {st }}$ century skills, the ER4STEM partners focused on the development of a specific set of skills through the project activities. In particular, ESI CEE, through this educational robotics workshop, aims to use robotics as a tool for the cultivation and development of communication, collaboration and digital fluency, which are among the most important $21^{\text {st }}$ century learning skills. Bellow we present an overview of these three skills and how we approach them through the ER4STEM project.

By collaboration skill, we refer to the ability of students to work effectively and respectfully with others. More specifically to a) contribute constructively to project teams b) be helpful and make necessary compromises to accomplish a common goal c) assume shared responsibility and value the individual contributions when working in a team d) use collaborative technologies to connect and work with others (i.e. peers, experts or community members, etc.) globally. For the development of these skills, through the robotics workshops, we aim to create situations where students will have to work in teams, distribute roles and build a public artefact that will trigger discussions and argumentation. Having this pedagogical approach in mind, the authors of this workshop designed the activities correspondingly. More precisely, students in each team are changing roles during the implementation of the tasks, which enables them to learn more about working effectively and respectfully with others in order and to build relevantly complex robotics system.

Similarly, considering communication as a $21^{\text {st }}$ century skill, students should be able to communicate with others effectively. This includes the ability to a) articulate thoughts and ideas effectively using oral, written or nonverbal communication skills b) communicate complex ideas clearly and effectively c) publish or present content that customizes the message and medium for their intended audience d) utilize multiple media and technologies in order to communicate and know how to judge their effectiveness e) communicate effectively in diverse environments. The essence of the workshop presented here, requires from students to clearly communicate their plans, ideas and feelings to the other members of their group.

Finally, by the skill of digital fluency, we refer to the technological and sciencerelated knowledge of the students. Thus, digital fluency includes the ability to understand the fundamental concepts of technology operations and to know how to use digital technology and media as tools to research, organize, evaluate and communicate information. Through the activities of this workshop, students learn more about the core elements of a robot (technology), they construct a robot (technology \& engineering) and develop a visual program to control the robot in order to execute tasks (technology).

\section{Evaluation}

In order to evaluate ER4STEM activities, a mixed-method multiple-case study design was used. Data collection consisted of questionnaires, observations, reflections, interviews and artefacts of learning. For the purposes of this paper, we will focus on 
data collected through questionnaires at the end of the workshops, in order to answer the following questions:

1) Do educational robotics workshops inspire students' interests in STEAM?

2) Do educational robotics workshops support learners to develop digital fluency, communication and collaboration skills?

Although the focus-group interview data that was also collected at the end of each workshop, could be used to answer these questions, the questionnaire provides us with a broad understanding of all learners' perceptions of the workshops, rather than just a select few participants. The questionnaire primarily utilizes Likert-scale and yes/no questions and allows for analysis of the data between age groups, workshops and by gender.

The questionnaire was given to every student who had parental informed consent to participate in the research, at the end of the workshop. In total 381 students participated in the workshops and 312 students completed the questionnaire. Of these 170 were boys and 142 were girls. Not every question was answered by every student and, therefore, we also report in the Findings below the number of times a question was unanswered, for clarity.

\section{$4 \quad$ Findings}

In this section, we present the findings of the analysis of the questionnaires in relation to the research questions posed.

\section{1) Students liked the educational workshop activities and were inspired to do more educational robotics activities in future.}

The vast majority of the students reported the educational robotics workshop activities as interesting, fun and not very difficult.

Table 1. Aggregated students' feedback related to problems and their work with robots.

$\begin{array}{cccccc}\text { Strongly } & \text { Disa- } & \text { Neither } & & \text { Strongly } & \text { Blank } \\ \text { disagree } & \text { gree } & \begin{array}{c}\text { Agree Nor } \\ \text { Disagree }\end{array} & \text { Agree } & \text { agree } & \end{array}$

The problems we had to solve

were:

$\begin{array}{lcccccc}\text { Interesting } & 0 \% & 0 \% & 1 \% & 9 \% & 87 \% & 3 \% \\ \text { Difficult } & 40 \% & 24 \% & 18 \% & 8 \% & 7 \% & 4 \% \\ \text { Fun } & 1 \% & 1 \% & 2 \% & 11 \% & 84 \% & 2 \% \\ \begin{array}{l}\text { Working with robots was: } \\ \text { Interesting }\end{array} & 0 \% & 0 \% & 1 \% & 7 \% & 89 \% & 3 \% \\ \begin{array}{l}\text { Difficult } \\ \text { Fun }\end{array} & 39 \% & 26 \% & 16 \% & 6 \% & 6 \% & 6 \% \\ & 0 \% & 0 \% & 1 \% & 7 \% & 88 \% & 4 \%\end{array}$


The students reported a very high level of overall satisfaction from the workshops (4.9 of $\max 5.0$ ), $90 \%$ of the students reported that they "would like to try to solve more challenges like this one" and the same share (90\%) of the students "would like to do more activities like this one".

2) The majority of students, who participated in the workshops reported an improvement in their skills in technology and science and consider robotics as an interesting and important subject.

Technology and science were reported as the leading knowledge fields applied and further developed during the workshops followed by "How the things work".

Table 2. Knowledge applied during the workshops

Working with robots I have used my knowledge of...

$\begin{array}{lc}\text { Science } & 73 \% \\ \text { Technology } & 84 \% \\ \text { Art } & 29 \% \\ \text { How things work } & 66 \% \\ \text { Mathematics } & 54 \% \\ \text { Working with robots has helped me to learn more about... } & \\ \text { Science } & 69 \% \\ \text { Technology } & 87 \% \\ \text { Art } & 24 \% \\ \text { How things work } & 64 \% \\ \text { Mathematics } & 36 \%\end{array}$

Moreover, students reported in the questionnaires an increased interest towards studying science and learning about how things work.

Table 3. Interest towards STEM

I am now more interested in studying science $\quad 89 \%$

I am now more interested in learning about how things work $91 \%$

I would like to build robots to solve problems in the future $80 \%$

I would like to use robots to learn in the future $90 \%$

Now I understand how important mathematics is $\quad 74 \%$

Now I understand how important science is $\quad 84 \%$

I would like to learn more about programming $\quad 88 \%$

I understand how robots can be used to solve important problems $\quad 77 \%$ 
It is interesting to mention that although encouraging the development of mathematical skills and interest was not directly targeted as workshops goals, the majority of the students $-74 \%$ reported that they "understand how important mathematics is" (Error! Reference source not found.). Another 54\% of the students stated that they applied their knowledge in mathematics to solve the workshop tasks. A further $36 \%$ reported, "Working with robots has helped me to learn more about mathematics".

\section{3) Good cooperation and collaboration.}

The majority of students reported working in a team as interesting, fun and not difficult (Table 5). Most of the students manifested positive attitudes towards aspects of teamwork, such as communication and collaboration.

Students generally enjoyed working as a part of a team, helping others and felt encouraged by their teams. To support that, students mostly showed disagreement with attitudes that do not support teamwork, communication and collaborations such as "working on my own", giving up quickly, or being bored.

Table 4. Working in a team, communication and collaboration

\begin{tabular}{|c|c|c|c|c|c|c|}
\hline & $\begin{array}{l}\text { Strongly } \\
\text { disagree }\end{array}$ & $\begin{array}{l}\text { Disa- } \\
\text { gree }\end{array}$ & $\begin{array}{c}\text { Neither } \\
\text { Agree Nor } \\
\text { Disagree }\end{array}$ & Agree & $\begin{array}{l}\text { Strongly } \\
\text { agree }\end{array}$ & Blank \\
\hline \multicolumn{7}{|l|}{ Working in a team was: } \\
\hline Interesting & $1 \%$ & $1 \%$ & $5 \%$ & $14 \%$ & $75 \%$ & $4 \%$ \\
\hline Difficult & $45 \%$ & $20 \%$ & $16 \%$ & $4 \%$ & $9 \%$ & $5 \%$ \\
\hline Fun & $2 \%$ & $1 \%$ & $4 \%$ & $14 \%$ & $76 \%$ & $4 \%$ \\
\hline \multicolumn{7}{|l|}{ During the workshop ...- } \\
\hline I worked as part of a team & $2 \%$ & $0 \%$ & $5 \%$ & $11 \%$ & $78 \%$ & $4 \%$ \\
\hline I worked on my own & $65 \%$ & $18 \%$ & $6 \%$ & $3 \%$ & $5 \%$ & $3 \%$ \\
\hline I helped design a robot & $6 \%$ & $3 \%$ & $10 \%$ & $20 \%$ & $56 \%$ & $5 \%$ \\
\hline I helped create a robot & $3 \%$ & $4 \%$ & $2 \%$ & $18 \%$ & $67 \%$ & $5 \%$ \\
\hline I helped program a robot & $3 \%$ & $1 \%$ & $6 \%$ & $16 \%$ & $71 \%$ & $4 \%$ \\
\hline \multicolumn{7}{|c|}{ I was able to choose what I wanted } \\
\hline to do & $14 \%$ & $7 \%$ & $18 \%$ & $15 \%$ & $42 \%$ & $4 \%$ \\
\hline $\begin{array}{l}\text { I feel that other people did not } \\
\text { ten to me }\end{array}$ & $38 \%$ & $13 \%$ & $16 \%$ & $9 \%$ & $21 \%$ & $4 \%$ \\
\hline I did most of the work & $29 \%$ & $19 \%$ & $25 \%$ & $9 \%$ & $13 \%$ & $5 \%$ \\
\hline I was encouraged by my team & $7 \%$ & $5 \%$ & $14 \%$ & $22 \%$ & $49 \%$ & $3 \%$ \\
\hline I was bored & $71 \%$ & $13 \%$ & $5 \%$ & $2 \%$ & $3 \%$ & $6 \%$ \\
\hline $\begin{array}{l}\text { I liked sharing what I had d } \\
\text { with other people }\end{array}$ & $2 \%$ & $1 \%$ & $9 \%$ & $16 \%$ & $68 \%$ & $3 \%$ \\
\hline
\end{tabular}


I helped someone

I gave up too quickly $\begin{array}{rr}6 \% & 3 \% \\ 71 \% & 13 \%\end{array}$

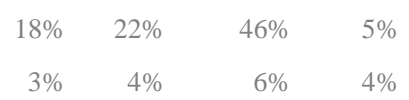

\section{Conclusions}

In this article, we presented our experience with applying educational robotics as a tool to enhance the learning of science, technology, engineering subjects and mathematics, as well as a tool to cultivate $21^{\text {st }}$ century skills in a constructionist setting. This brief overview of a fraction of the data received by students was shared, to serve as a positive example of the opportunities from the application of educational robotics as a tool for introducing general education subjects. The following research questions were derived and postulated:

\section{Do educational robotics workshops inspire students' interests in STEAM?}

According to the data received, students feel more inclined to study the science, technology, engineering subjects and mathematics following the workshops. The educational robotics workshops showcase the combined product of the application of the above-mentioned subjects in an appealing and intriguing way. Assembling a complex robot provides the space necessary for students to construct their own knowledgebased structures, thus enabling them to explore new ideas and express their creativity.[5]

Do educational robotics workshops support learners to develop digital fluency, communication and collaboration skills?

This paper overviewed the design of an educational robotics workshop, formulated around the pedagogical concept of constructivism to support the development of $21 \mathrm{st}$ century skills. Namely, the target skills, which this educational robotics workshop aims to develop are creativity, communication, collaboration and digital fluency. Empirical data to support the conclusion that educational robotics has the capacity to positively influence, and thusly to support, young learners to cultivate skills and knowledge in digital fluency, communication and collaboration, was presented.

The design of the evaluation of this workshop presents an opportunity for the participants to reflect on particular concepts, related to 21 st century values, for example teamwork. Students show a tendency to enjoy the teamwork aspects of the workshop.

The workshop's aims to support a constructionist setting of working in groups to engage students in tasks, requiring abilities, such as clearly communicating ideas, voicing out concerns, proposing solutions, based on pre-existing knowledge. The workshop's educational plan, by design, involves covering main stepping-stones of digital fluency.

The empirical data collected through the post workshop questionnaires does not provide information about if the workshop develop creativity. The authors are researching 
the artefacts and are analysing interviews and observation to answer this question, which will be discussed in a separate paper.

\subsection{Feedback from schools and educational institutions}

Among the reasons to determine the constructionist approach in education as one of an increasing appreciation, is the positive feedback on the learning methodology from schools, educational authorities and academic partners.

Most of the schools, where the workshops were implemented, are now strong supporters of the idea of constructionist education and the application of robotics tools in education. Receiving good feedback from schools on the activities and establishing sustainable partnerships with the schools could serve as an indicator for the positive results from the educational activities.

Among the examples is 125 High School "Boyan Penev", which, inspired by the outcomes of the workshop and the positive feedback from students and parents, used the gained experience to formally become an innovative school in Bulgaria and embrace the constructionist approach as an inseparable part of their educational curricula.

Partners from the Mathematics Gymnasium in Kiustendil, with the support of the city mayor and the municipality, decided on applying and further developing this educational robotics workshop in their school. Teachers and representatives from the school attended educational robotics workshops in Sofia on multiple occasions and decided upon organizing it locally at the gymnasium. For this purpose, they are currently training their teachers on the particularities of the workshop with the support of ESI CEE.

The European Software Institute - Center Eastern Europe has also received positive feedback from other counties on the educational robotics workshop. Moldovan partners are currently in the process of organizing train-the-trainer activities in Moldova aiming to implement this educational technology in more than 10 schools.

\subsection{Current work and future prospects}

Based on tutor reflections and students' feedback, the European Software Institute Center Eastern Europe improved some hardware issues, making the assembly of the robot more pleasant. Such improvements are enhancing the stability of the battery holders by changing the design of the pins, ensuring stability of the ultrasonic sensors and the microcontroller, when the robot is in operation.

Various aspects of the visual guide for the assembly of the robot were changed to make it clearer and easier to navigate through in order to further facilitate the collaboration among the team members. Furthermore, software solutions were researched and implemented to make fixing issues during operation quicker, as well as to improve the functionalities, along with the usability for both tutors and students.

The improved activity plans and evaluation protocol, kit and tools made the process of obtaining feedback from the students easier, quicker and more effective in terms of the ER4STEM project goals. 
Moreover, based on the positive experience gained throughout the organization and successful implementation of this series of educational robotics workshops, ESI CEE was inspired to create another educational robotics workshop. "Visualizing mathematics with the Mathbot" already has more than 160 successfully trained participants with even higher level of students' appreciation. This workshop aims to build on the educational robotics for creativity workshop. Using the Finch Robot by BirdBrain Technologies LLC., and by applying more advanced programming tasks it aims to encourage positive attitudes towards learning mathematics by teaching, demonstrating and exercising in practice students' knowledge on the basic mathematical concepts, in support to the Bulgarian national educational curriculum on mathematics for the $4^{\text {th }}$ grade.

The sustainable partnerships, established with our academic partner, allow us to continue improving and developing new educational technologies, based on robotics and programming to support general education.

With multiple international stakeholders showing interest and appreciation of the technology, we firmly believe that educational robotics has the power to reform insurrectionism and result in the implementation of constructionist practices for improving learning outcomes and contributing to quality education.

Acknowledgments. The project has received funding from the European Union's Horizon 2020 research and innovation program under grant agreement No. 665972. Project Educational Robotics for STEM: ER4STEM

\section{References}

1. Papert, S. (1980). Mindstorms: Children, computers, and powerful ideas. Basic Books, Inc.

2. Kafai, Y. B., \& Burke, Q. (2015). Constructionist Gaming: Understanding the Bene-fits of Making Games for Learning. Educational Psychologist, 50(4), 313-334. https://doi.org/10.1080/00461520.2015.1124022

3. Kafai, Y. B., Burke, Q., \& Mote, C. (2012). What makes competitions fun to partic-ipate?: the role of audience for middle school game designers. In Proceedings of the 11th International Conference on Interaction Design and Children (pp. 284-287). ACM. Retrieved from http://dl.acm.org/citation.cfm?id=2307146

4. Nikoleta Yiannoutsou, Sofia Nikitopoulou, Chronis Kynigos, Ivaylo Gueorguiev, and Julian Angel Fernandez, Activity plan template: A mediating tool for supporting learning design with robotics, pp. 3-13, Springer International Publishing, Cham, 2017.

5. I.R. Management Association, Robotics: Concepts, methodologies, tools, and applications: Concepts, methodologies, tools, and applications, Information Science Reference, 2013. 